\title{
Impact of Mental Health Education on Health Attitude among In- School Adolescents in Kogi State Nigeria
}

\author{
Jacob, Funso Florence (Ph. D) \\ Department Of Human Kinetics and Health Education Faculty Of Education University Of Ibadan, Oyo State, \\ Nigeria
}

\begin{abstract}
In-school adolescents have been observed to face challenges of health problems and premature death globally Because of their unhealthy attitudes. These may include poor attitudes to smoking, alcohol consumption, interpersonal violence, poor eating habit, anxiety and multiple sex partners. Mental health education has been shown to have the potential of enhancing ability to control such attitudes which previous studies of prevalent risky health problems among adolescents have not been able to solve. This study therefore, examined the impact of mental health education on health attitude among in-school adolescents in Kogi State Nigeria. The pretest-posttest quasi-experimental design of $2 \times 2 \times 2$ Factorial Matrix was adopted for the study. Table of random numbers were used to select 436 participants (209 males and 227 females) and four public secondary schools in Lokoja Township, Kogi State. Participants were randomly assigned to experimental and control groups. The experimental group was exposed to the mental health education programme for 8 weeks while the control was not given any treatment. The instrument used for this study was a Mental Health Education Attitude Scale $(r=0.75)$ Seven hypotheses were tested at 0.05 level of significance. Data were subjected to Analysis of Covariance. A significant difference was found in the 2-way interaction impact of gender and religion $\left(F_{(1,427)}=15.61 ; p<.05\right)$. Christian males performed better $\left(\boldsymbol{x}^{-}=62.43\right)$ than females $\left(\boldsymbol{x}^{-}=61.05\right)$ but females performed better $\left(\boldsymbol{x}^{-}=63.63\right)$ than males $\left(\boldsymbol{x}^{-}=58.71\right)$ among Muslims. Also 3-way interaction impact of treatment, gender and religion on health attitude $\left(F_{(1,435)}=5.43 ; p<.05\right)$ was significant. However, significant impact was not found between experimental and control groups health attitude $\left(F_{(1,427)}=\right.$ .27; $p>.05)$. But participants in control group obtained slightly higher score $(\overline{\boldsymbol{x}}=61.74)$ than their treatment group $(\overline{\boldsymbol{x}}=61.44)$. Also significant impact was not found in health attitudes on gender $\left(F_{(1,427)}=2.92 ; p>.05\right)$ and religion $\left.F_{(1,247)}=2.92 ; p>.05\right)$. However, females obtained slightly higher adjusted score $(\bar{x}=62.11)$ than males $(\bar{x}=61.02)$ and Christians obtained slightly higher adjusted posttest attitude scores $\left(\boldsymbol{x}^{-}=61.78\right)$ than Muslim $(\bar{x}=61.23)$. It was observed that mental health education is effective in enhancing in-school adolescents' health attitude. Mental health education should therefore be introduced into the secondary school curriculum.
\end{abstract}

Key words: In-school adolescents, Mental health education, Health attitude, Gender, Religion

\section{Introduction}

Unhealthy attitudes may include negative feeling and thought that can predispose to stress and tension, risky life styles like substance use, poor dietary habits, unprotected and premature sexual acts and debased regular physical exercises. The ability to think clearly, examine problems and identify responsible and reasonable solutions by either seeking assistance or taking positive steps about life situations that may lead to health problems depends on positive mental health. Mental healthiness refers to the ability to be able to control ones thoughts, feelings and behaviours, and as well feel good about self and be in good relationship with others.

Holmes (2010); Gale Encyclopedia of Public Health (2011) stressed extensively that mental or emotional health are terms that generally refer to our thoughts, feelings and actions, including the capacity to think rationally and logically, and to cope with the transitions, stresses, traumas, and losses that occur in all lives, in ways that allow emotional stability and growth particularly when faced with a kind of life's challenges and stress.

Mental health is the foundation of our thinking and communication skills, learning, emotional growth, resilience and self-esteem. As such emotionally balanced individual should be able to live a full and creative life, and be flexible to deal with life's inevitable challenges. However this does not imply the absence of distress and suffering, or strict societal conformity but how these situations are handled. Therefore mental health is about idiosyncratic beliefs and delusions, sadness and depression, worry and severe anxiety which are essential criteria for defining behavioural patterns or symptoms of psychological distress as a mental disorder.

Nonetheless, appropriate school mental health education can help counteracting state of poor mental health especially among adolescents. Moreover mental health education programme is an aspect of the entire health education programme which deals with development and maintenance of desirable healthy life styles. 
Rae, Sullivan, Razo, George, and Ramirez, (2001) showed that about 18\% adolescents experience emotional distress and nearly $4 \%$ have attempted suicide. In their survey of high school students, over $12 \%$ thought about killing or hurting themselves. Unfortunately, parents do not always recognize their adolescent's underlying emotional distress, as these feelings are much harder to detect than overt behaviours. Tobacco use, alcohol use, drug use, sexual, suicidal poor sexual behaviours can clearly have negative effects on adolescents' health. Also traumatic events such as childhood abuse or neglect, violence and non-traumatic stressors, anxiety problems, nutritional deficiencies (such as deficient vitamin B12), unwanted pregnancy, inadequate parenting and secured attachments to caretakers, coupled with STI infections (such as syphilis and HIV/AIDS (human immunodeficiency virus/acquired Immune Deficiency Syndrome) can all threaten mental stability and cause mental disorder during adolescence. Britsch and Olson (2001) submitted that adolescence is a period when young people undergo radical changes in physiology, attitudes and social relationships as they grow from childhood to adulthood. Adolescent begins when puberty sets in and ends in the early twenties when the person is reasonably independent from his parents. Adolescents go through accelerated physical growths leading to changes in self-concept; psychological challenge of becoming independent and establishing own identity and learning about ones capabilities and limitations happens to adolescents during this period. There is also a strong desire for social support from peers thereby making them vulnerable to the risks associated with feelings of social isolation which may contribute to the occurrence of poor mental health during adolescence Britsch and Olson (2001).

American Educational Research Association (2000-2011) reported that the whole education and indeed the whole mental hygiene of children including adolescents turn upon the solutions sought and found to the twin problems of maintaining personal sway and of moving forward to resolve the continual challenges presented by the environment, on the cultural or social scene. Health education is any combination of learning experiences designed to help individuals and communities to improve their health. Whereas mental Health refers to a broad array of activities directly or indirectly related to the mental well-being component included in the World Health Organisation's definition of health: "A state of complete physical, mental and social well-being, and not merely the absence of disease". This is related to the promotion of well-being, the prevention of mental disorders, and the treatment and rehabilitation of people affected by mental disorders. Skilled based approach health education is assumed be more effective to tackle these problems than teaching knowledge alone.

Skill based health education approach focuses upon the development of attitudes, and values (including life skills such as inter-personal skills, critical and creative thinking, decision making and self awareness) needed to make and act on the most appropriate and positive health-related decisions. Adequate attention has to be taken to change and prevent factors that can impede adolescents' potentials which may result from wrong development of personality, self-efficacy and health attitude during their developmental stage.

During early adolescence, as boys and girls develop different explanatory styles, they also develop different styles of coping with stressful situations. Some studies also revealed that boys and girls react differently to same issues and there are consistent gender differences in health behaviours. For instance among adolescents, more boys have unhealthy drinking and eating habit, different depressant factors, and different sexual arousal and habits than girls (Gurian 2011). The result from the 2003 National survey on substance use and health (SAMHSA 2004) revealed that $57.3 \%$ of male aged 12 or older was currently dependent on psychoactive substances compare with $43.2 \%$ of females. However among the individuals between the ages of 12 and 17, males and females had comparable rate of alcohol use (17.1\% of males and $18.3 \%$ of females).

Similarly the National survey on drug use and health (SAMHSA 2004) revealed that more males ( $28.1 \%$, than females $23.0 \%$ ) aged 12 or older smoked cigarette in 2003; but respondents between the ages of 12 and 17 comparable smoking rates were observed for boys and girls $(11.9 \%$ vs $12.5 \%$ respectively). The study further indicated that the rate of substance use among females $(8.7 \%)$ was not significantly different from the rate among males (9.1\%) for respondents between the ages of 12-17.

Furthermore, Fagan (2006); National Institute of Health Guide (2003); Burdette and Hill (2011) reviewed that religion reduces the likelihood of adolescents engaging in early sex by shaping their attitudes and beliefs about sexual activity. They agreed that adolescents who frequently attend religious services and have a high level of spiritual support from others in their community have the lowest levels of depression. Also, in a 2002 review of the academic literature on the effects of religion, 97 percent of the studies reported significant correlations between increased religious involvement and a lower likelihood of promiscuous sexual behaviours. Science Daily News (2008), referred to the idea of Richard Petts (co-author) who is of the opinion that participating in religious activities at high levels may be detrimental to teens because of the tensions they face in balancing the conflicting ideals and customs of their religion with those mainstream cultures. 


\section{Statement Of The Problem}

Male and female adolescents of secondary schools age in Kogi State develop negative thoughts and view toward certain health issues that can damage and destroy their health. Most of these adolescents do not perceive any danger in engaging in substance use (cigarette smoking, marijuana smoking and alcohol consumption), interpersonal violence, poor eating habit, anxiety, and multiple sex partners. These attitudes can predispose them to diseases and health problems or reduce their life expectancy. Most of these adolescent problems have been adequately attended to with little understanding of the potential impact the problems may have in the life of these adolescents and their society in future. In view of these factors, the research study determined the impact of mental health education on health attitudes among in-school adolescents' in Kogi State, Nigeria. This also found how gender and religion can influence the attitudes of in-school adolescents. It also provides maximum efforts to design programmes that can impact positive changes on selected health problems of secondary schools adolescents in Kogi State, Nigeria.

\section{Hypothseses}

1 There is no significant impact in the attitudes of in-school adolescents' exposed to mental health education on cigarette smoking, alcohol consumption, marijuana smoking, interpersonal violence, poor eating habit, anxiety, and multiple sex partners and those in the control group.

2 There is no significant impact in the attitudes of male/female (gender) in-school adolescents' exposed to mental health education mental health education on cigarette smoking, alcohol consumption, marijuana smoking, interpersonal violence, poor eating habit, anxiety, and multiple sex partners and those in the control group.

3 There is no significant impact in the attitudes of Christian/Muslim (religion) in-school adolescents' exposed to mental health education on cigarette smoking, alcohol consumption, marijuana smoking, interpersonal violence, poor eating habit, anxiety, and multiple sex partners and those in the control group.

4 There is no significant 2-way interaction impact of treatment on male/female (gender) in-school adolescents' exposed to mental health education attitude on cigarette smoking, alcohol consumption, marijuana smoking, interpersonal violence, poor eating habit, anxiety, and multiple sex partners and those in the control group.

5 There is no significant 2-way interaction impact of treatment on Christian/Muslim (religion) in-school adolescent exposed to mental health education attitude on cigarette smoking, alcohol consumption, marijuana smoking, interpersonal violence, poor eating habit, anxiety, and multiple sex partners and those in the control group.

6 There is no significant 2-way interaction impact of treatment on male/female (gender) and Christian/Muslim (religion) in-school adolescent exposed to mental health education attitude on cigarette smoking, alcohol consumption, marijuana smoking, interpersonal violence, poor eating habit, anxiety, and multiple sex partners and those in the control group.

7 There is no significant 3-way interaction impact of treatment on male/female (gender) and Christian/Muslim (religion) in-school adolescent exposed to mental health education attitude on cigarette smoking, alcohol consumption, marijuana smoking, interpersonal violence, poor eating habit, anxiety, and multiple sex partners and those in the control group.

\section{Methodology}

The research design for the study is a pretest-posttest quasi-experimental Ex-post Facto $2 \times 2 \times 2$ Factorial Matrix design. The population for the study comprised all coeducational Senior Secondary School students in Kogi State of Nigeria. The sample was 436 (209 males and 227 females) male and female students in senior secondary school II (SSS II) from the four (4) sampled schools in public coeducational (male and female) schools in Lokoja Township from Kogi State. Simple random sampling technique was used to select four (4) schools in Lokoja Township and Micro Soft Excel Rand Function was used to select the participants from the sampled schools.

The instruments used for this study was self developed, structured and validated Mental Health Education Attitude Scale $(r=0.75)$. Data gathered for the study were was set at 0.05 alpha level of significant and analyzed using inferential statistics of Analysis of Co-variance (ANCOVA).

\section{Presentation of Result}

Ho 1: There is no significant impact in the attitudes of in-school adolescents' exposed to mental health education on cigarette smoking, alcohol consumption, marijuana smoking, interpersonal violence, poor eating habit, anxiety, and multiple sex partners and those in the control group. 
Table 1: Summary of ANCOVA of Posttest Attitude Score by Treatment, Gender and Religion.

\begin{tabular}{|c|c|c|c|c|c|c|}
\hline \multirow{2}{*}{\multicolumn{2}{|c|}{ Source of Variance }} & \multirow{3}{*}{$\begin{array}{l}\begin{array}{l}\text { Sum of } \\
\text { Squares }\end{array} \\
173.137 \\
174.059 \\
12.216 \\
132.197 \\
29.645 \\
\end{array}$} & \multicolumn{4}{|c|}{ Hierarchical Method } \\
\hline & & & Df & Mean & $\mathbf{F}$ & Sig \\
\hline $\begin{array}{l}\text { Covariates } \\
\text { Main Effects }\end{array}$ & $\begin{array}{l}\text { Attitude } \\
\text { (Combined) } \\
\text { TREATMENT } \\
\text { GENDER } \\
\text { RELIGION } \\
\end{array}$ & & $\begin{array}{l}1 \\
3 \\
1 \\
1 \\
1 \\
\end{array}$ & $\begin{array}{l}173.137 \\
58.020 \\
12.216 \\
132.197 \\
29.645 \\
\end{array}$ & $\begin{array}{l}3.827 \\
1.282 \\
.270 \\
2.922 \\
.655\end{array}$ & $\begin{array}{l}.051 \\
.280 \\
.604 \\
.088 \\
.419 \\
\end{array}$ \\
\hline 2-way Interactions & $\begin{array}{l}\text { (Combined) } \\
\text { TREATMENT } \\
\text { x GENDER } \\
\text { TREATMENT } \\
x \\
\text { RELIGION } \\
\text { GENDER } x \\
\text { RELIGION }\end{array}$ & $\begin{array}{l}813.605 \\
54.248 \\
16.372 \\
706.070\end{array}$ & $\begin{array}{l}3 \\
1\end{array}$ & $\begin{array}{l}271.202 \\
54.248 \\
16.372 \\
706.070\end{array}$ & $\begin{array}{l}.994 \\
1.199 \\
.362 \\
15.606\end{array}$ & $\begin{array}{l}.001 \\
.274 \\
\end{array}$ \\
\hline 3 -way Interactions & $\begin{array}{l}\text { TREATMENT } \\
\mathrm{x} \text { GENDER } \mathrm{x} \\
\text { RELIGION }\end{array}$ & 245.526 & 1 & 245.526 & 5.427 & $.000^{*}$ \\
\hline $\begin{array}{l}\text { Model } \\
\text { Residual } \\
\text { Total } \\
\end{array}$ & & $\begin{array}{l}1406.328 \\
19319.532 \\
20725.860 \\
\end{array}$ & $\begin{array}{l}8 \\
427 \\
435 \\
\end{array}$ & $\begin{array}{l}175.791 \\
45.245 \\
47.646 \\
\end{array}$ & 3.885 & .000 \\
\hline
\end{tabular}

Significant of $\mathrm{p}<.05$

Table 1 shows that there is no significant impact of treatment on students' attitude to mental health education $\left(\mathrm{F}_{(1,427)}=.27 ; \mathrm{p}>.05\right)$. This means that the impact in the adjusted posttest mental health education attitude score of students in the treatment group and those in the control group is not significant hence, hypothesis 1 is not rejected.

Table 1 however presents the magnitude of the respective mean scores obtained by the different groups.

Table 2: Multiple Classification Analysis of Posttest Attitude Scores by Treatment, Gender and Religion. Grand mean $=61.5$

\begin{tabular}{|c|c|c|c|c|c|c|c|c|}
\hline & & \multirow[b]{2}{*}{$\mathbf{N}$} & \multicolumn{2}{|c|}{ Predicted mean } & \multicolumn{2}{|l|}{ Deviation } & \multirow[b]{2}{*}{ Eta } & \multirow[b]{2}{*}{$\begin{array}{l}\text { Bet } \\
\text { a }\end{array}$} \\
\hline \multicolumn{2}{|c|}{ Variable + category } & & Unadjusted & $\begin{array}{l}\text { Adjusted } \\
\text { for factor }\end{array}$ & Unadjusted & $\begin{array}{l}\text { Adjusted } \\
\text { for factors }\end{array}$ & & \\
\hline TREATMENT & $\begin{array}{l}\text { Intervention } \\
\text { Control }\end{array}$ & $\begin{array}{l}225 \\
211\end{array}$ & $\begin{array}{l}61.7067 \\
61.4550\end{array}$ & $\begin{array}{l}61.4387 \\
61.7407\end{array}$ & $\begin{array}{l}.1218 \\
-.1299\end{array}$ & $\begin{array}{l}-.1462 \\
.1559\end{array}$ & $\begin{array}{l}.01 \\
8\end{array}$ & .022 \\
\hline GENDER & $\begin{array}{l}\text { Male } \\
\text { Female }\end{array}$ & $\begin{array}{l}209 \\
227\end{array}$ & $\begin{array}{l}61.0622 \\
62.0661\end{array}$ & $\begin{array}{l}61.0171 \\
62.1076\end{array}$ & $\begin{array}{l}-.5227 \\
\wedge .4812\end{array}$ & $\begin{array}{l}.5678 \\
.5228\end{array}$ & $\begin{array}{l}.07 \\
3\end{array}$ & .079 \\
\hline RELIGION & $\begin{array}{l}\text { Christianity } \\
\text { Islam }\end{array}$ & $\begin{array}{l}281 \\
155\end{array}$ & $\begin{array}{l}61.8043 \\
61.1871\end{array}$ & $\begin{array}{l}61.7808 \\
61.2297\end{array}$ & $\begin{array}{l}.2194 \\
-.3978\end{array}$ & $\begin{array}{l}.1959 \\
-.3551\end{array}$ & $\begin{array}{l}.04 \\
3 \\
\end{array}$ & .038 \\
\hline \multicolumn{9}{|l|}{$\mathrm{R}=.129$} \\
\hline $\begin{array}{l}\mathrm{R} \text { Squared }= \\
.017\end{array}$ & & & & & & & & \\
\hline
\end{tabular}

Table 2 shows that the control group obtained slightly higher adjusted posttest mean attitude score $(\overline{\mathbf{x}}=61.74 ;$ adj. dev $=.16)$ than their treatment group counterparts $(\overline{\mathbf{x}}=61.44 ;$ adj. dev.$=.15)$.

Ho2: There is no significant impact in the attitudes of males/female (gender) in-school adolescents' exposed to mental health education mental health education on cigarette smoking, alcohol consumption, marijuana smoking, interpersonal violence, poor eating habit, anxiety, and multiple sex partners and those in the control group.

Table 1 shows that there is no significant impact of gender on students' attitudes to mental health education $\left(\mathrm{F}_{(1,427)}=2.92 ; \mathrm{p}>.05\right)$. Hence, hypothesis 2 is not rejected.

From Table 2, however, female students obtained slightly higher adjusted posttest mean attitude score. $(\overline{\mathrm{x}} 62.11 ;$ adj. dev. $=.52)$ than the male conterparts $(\overline{\mathrm{x}}=61.02 ;$ adj. dev. $=-57)$.

Ho3: There is no significant impact in the attitudes of Christian/Muslim (religion) in- school adolescents' exposed to mental health education on cigarette smoking, alcohol consumption, marijuana 
smoking, interpersonal violence, poor eating habit, anxiety, and multiple sex partners and those in the control group.

Table 1 shows that there is no significant impact of religion on students' attitudes to mental health education $\left(\mathrm{F}_{(1,247)}=2.92 ; \mathrm{p}>.05\right)$. On this basis, hypothesis 3 is not rejected.

Further, Table 2 shows that the Christians participants in the study obtained slightly higher adjusted posttest attitude scores $(\overline{\mathbf{x}}=61.78 ;$ adj.dev. $=.19)$ than their Muslim counterparts $(\overline{\mathrm{x}}=61.23 ;$ adj. $\operatorname{dev}=-.36)$.

Ho 4: There is no significant 2-way interaction impact of treatment on males/females (gender) inschool adolescents' exposed to mental health education attitude on cigarette smoking, alcohol consumption, marijuana smoking, interpersonal violence, poor eating habit, anxiety, and multiple sex partners and those in the control group.

From Table 1, there is no significant 2-way interaction impact of treatment and gender on students' attitude to mental health education $\left(\mathrm{F}_{(1,427)}=1.19 ; \mathrm{p}>.05\right)$. Hence, hypothesis 4 is not rejected.

Ho5: There is no significant 2-way interaction impact of treatment on Christian/Muslim (religion) inschool adolescent exposed to mental health education attitude on cigarette smoking, alcohol consumption, marijuana smoking, interpersonal violence, poor eating habit, anxiety, and multiple sex partners and those in the control group.

Table 1 shows that the 2-way interaction impact of treatment and religion on students' attitudes to mental health education is not significant $\left(\mathrm{F}_{(1,427)}=.36 ; \mathrm{p}>.05\right)$. Hypothesis 5 is not rejected.

Ho 6: There is no significant 2-way interaction impact of treatment on male/female (gender) and Christian/Muslim (religion) in-school adolescent exposed to mental health education attitude on cigarette smoking, alcohol consumption, marijuana smoking, interpersonal violence, poor eating habit, anxiety, and multiple sex partners and those in the control group.

Table 1 shows that the 2-way interaction impact of gender and religion on students' attitude to mental health education is significant $\left(\mathrm{F}_{(1,427)}=15.61 ; \mathrm{p}<.05\right)$. On this basis, hypothesis 6 is rejected.

Figure 1: Interaction Effect of Gender and Religion on Attitude of Mental Health Education Participants.

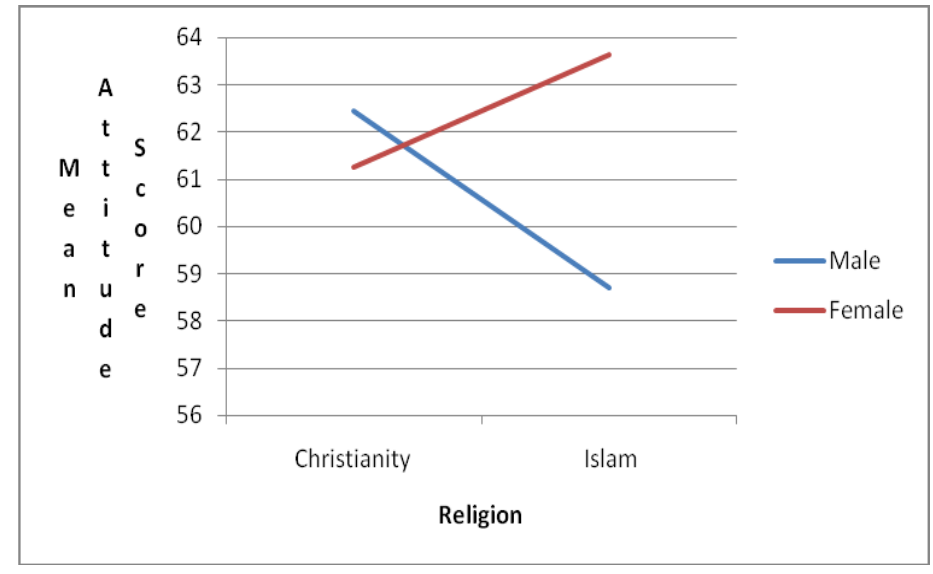

Figure 1 shows that among the Christian students males had higher attitude mean score $(\overline{\mathbf{x}}=62.43)$ than the female $(\overline{\mathbf{x}}=61.05)$. However, among the Muslims, the females had higher attitude score $(\overline{\mathbf{x}}=63.63)$ than the males $(\overline{\mathbf{x}}=58.71)$. This interaction is a disordinal interaction.

Ho7: There is no significant 3-way interaction impact of treatment, on male/female (gender) and Christian/Muslim (religion) in-school adolescent exposed to mental health education attitude on cigarette smoking, alcohol consumption, marijuana smoking, interpersonal violence, poor eating habit, anxiety, and multiple sex partners and those in the control group.

From Table 5.3, the 3-way interaction impact of treatment, gender and religion on students' attitude to mental health education is significant $\left(\mathrm{F}_{(1,427)}=5.43 ; \mathrm{p}<.05\right)$. Hypothesis $7 \mathrm{~b}$ is therefore rejected.

\section{Discussion}

This study found that the impact in the adjusted posttest mental health education attitude score of students in the treatment group and those in the control group is not significant. Here, the control group obtained slightly higher adjusted posttest mean attitude score than their treatment counterparts. This does not mean that adolescents cannot have a change of attitude with the aid of appropriate skills and effective teaching methods because comprehensive school health teaching is based on assisting students in the development of healthful 
attitudes. The reason may not be far from the non chanlant attitudes of parents and the society to these adolescents' ways of living. Most of these students live with their parents or relatives but they still develop wrong attitudes that are detrimental to their health without the elderly ones rebuking and correcting them. And home is the first socializing institution that could provides adolescents the personality that would continue throughout life time. As the expression by Awoniyi (2003) states that "charity begins at home" and home is the cradle of discipline as the oldest and most unique human institution.

There is no significant impact of gender on students' attitude. Female students obtained slightly higher adjusted posttest mean attitude score than their male counterparts. Probably due to traditional belief that males enjoy more power than women in virtually all the major institutions: politics, religion, economics, and family.

The indulgences in negative attitude by males tend to be more tolerated and even encouraged than females. Whereas the female negative attitudes are more controlled and subject to censure of violation of norms. International Clinical Epidemiology Network (1998 - 2001) found that school-based intervention programme with the use of materials like fliers, talks, bulletin boards, posters, role play, peer discussion, video and peer counseling is very effective in positive attitudinal change is in support of the findings of this study.

Adolescents may comply with risky health attitudes because of the non charlatan attitudes of adolescents to their positive health or because of their erroneous beliefs which could affect their decision making. As Sokoya (2000) and Okanlawon (2004); Odekunle (2008) rightly mentioned that gender is an important factor in understanding attitudes towards issues. For example boys believe sexual intercourse is a key right to adulthood; males are more likely to initiate sexual activities, have more sex partners. Also boys have more permissive perception and believe that getting 'burnt' (contract STD), is a sign of initiation into manhood, and that urination after sexual intercourse will get rid of any infections. This is because this is considered a normative rite for boys, while girls tend to be labeled and stigmatized and are often blamed for sexual encounters that result in sexually transmitted infections or pregnancy.

There is no significant impact of religion on students' attitude to mental health education. The Christians in the study obtained slightly higher adjusted posttest attitude scores than their Muslim counterparts. The slight increase in the adjusted mean score may likely be because one of the schools where the programme took place was a Christian school and it is assumed that some religious teaching might have affected their attitude positively. This study is in line with the report of Regnerus (2005) who found that adolescents who frequently attend religious services and have a high level spiritual support from religious elders may not be depressed. Conversely, that lack of religious affiliation correlates with an increased risk of suicide among adolescents. The 2-way interaction impact of religion on students' attitude to mental health education was significant among the males Christians than the females and among females than males among Muslims. This does not mean the religious sectors are not doing anything about the life of their adolescents. Probably adolescents are not very serious about their religious life or that they are debased in the right teaching strategies. Also, males are generally very careless and less concern about what happens to their health than females. Some of them may not actually follow the teachings and trainings they receive from their religious leaders. Further, there is significant 3-way interaction effect of treatment gender and religion on students' mental health education attitude. These findings implied that mental health education is important and necessary if adolescents are to live a healthy life that will be free from health crisis and problems both at present and the nearest future.

\section{Conclusion}

The following conclusions were drawn based on the findings of the study:

Mental health education was perceived to be potent in effecting positive health attitude and successfully stemmed negative health attitude among in-school adolescents in the country and particularly Kogi State Nigeria. This would help to reduce the rate of anti-social attitude and ill-health that rampage life of adolescents now and the nearest future. Also the expenses of medical bills and cost of fighting crimes by the nation will be reduced to the barest minimum if adolescent health problems can be curbed.

\section{Recommendations}

1. Adolescents should be educated through school-based mental health education in conjunction with approved communication between parents and children for the development of positive health attitudes and behaviours. They should be provided with interesting and constructive mental health education inform of social recreational activities, psychological, social and nutritional counseling, including social clubs and organization, and vocational activities where they can associate with people and learn things that can contribute to their life positively. School counselors should seriously engage students in mental health education intervention programme.

2. Religious organizations should introduce mental health education activities into the developmental and learning processes of the adolescents to occupy them positively and prevent them from having time for unhealthy negative thoughts that could be detrimental to their health. 
3. Female Christians performed better in the programme than their Muslim counterparts; therefore Muslim organizations should improve more in the mental health education of their female adolescents.

4. Achievers and important personalities in religious settings could be invited to address and encourage students in schools on mental health practices.

5. However all stake holders in the life of adolescents that include religious organisations in conjunction with parents, teachers, government, social and health workers should endeavour to adequately and effective encourage adolescents on their ways of living to ensure a better society beside the provision of care, protection and social skills.

\section{References}

[1]. Awoniyi S.2003. Youth and national development; A socio-ethnical regeneration for our present age. Knowledge Review. 6 (1), 96.

[2]. Britsch R. L.and T, D. Olson T.D. 2001. Counseling: A guide to Helping Others. http//www.mentalhealthlibrary.info/library Retrieved 12/4/2008

[3]. Burdette AM. and Hill T.D. 2011. Religious involvement and transitions into adolescent sexual activities. http//www.socrel.oxfordjournals.org

[4]. Fagan P. 2006. Why Religion Matters Even More: The Impact of Religious Practice on Social Stability. Retrieved 9/12/2011 http://www.heritage.org/research/reports

[5]. Gale Encyclopedia of Public Health 20111. Mental health.answer.com http://www.answer.com 19-03-2011

[6]. Gurian A. 2011. Depression in Adolescence: Does Gender Matter?

[7]. http//.www.about.ourkids.org/article

[8]. Holmes L. 2010. What is mental health? About.com Guide. http://www.about.com Retrieved 19-3-2011

[9]. http://www.content4reprint.com.family/parenting/teenagers Retrieved 12/4/ 2008

[10]. International Clinical Epidemiology Network - INCLEN (1998 - 2001) Adolescent health.

[11]. http://www.inclen.org/research/ah.html retrieved 19/1/2010

[12]. Jacob F.F. 2012. Effect of mental health education on health Knowledge attitude and risky behaviours among in-school adolescents in kogi state, Nigeria. A Ph.D Thesis.

[13]. National Institute of Health Guide 2003. Maintenance of long behavioural change. Retrieve 31/10/2007 http://grants.nih.gov/series university of Ibadan page $2-3$

[14]. Odekunle, K., 2008. Education for millennium development, Nigeria: Ibadan. Spectrum Books Ltd, 36-51.

[15]. Okalawon F.A. 2004. Peer education: An effective tool for promoting positive change in adolescents' risky sexual behaviour. Contemporary Issues and Researches on adolescents. $1^{\text {st }}$ ed. Ibadan.Royal People Publication Nig ltd.

[16]. Population Report 1998. New Gather guide to Counseling. Geneva; WHO Series J48.

[17]. Rae W. A, Sullivan J. R, Razo N. P, George C. A. , and Ramirez E, 2001. Adolescent Health

[18]. Risk Behavior: When Do Pediatric Psychologists Break Confidentiality? http://www.ncbi.nlm.gov Retrieved 10-4-2011

[19]. Science DailyNews 2008. Participating in religion may make adolescents from certain races more depressed. www.sciencedaily.com/release

[20]. Sokoya G. O. 2000. Societal and environmental responsibility for girl child growth anddevelopment. Nigerian School Health Journal (NSHA) 12, (1\&2) 